\title{
PERFORACIONES RADICULARES: UNA REVISIÓN
}

Carlos Alberto Ojeda C

Odontólogo, U. Nacional, Residente de II año, posgrado de endodoncio, U. Santo Tomás.

Autor responsable de correspondencia: Dr. Carlos Alberto Ojeda C Correo electrónico: gerenciacao@hotmail.com

\begin{abstract}
RESUMEN
Las perforaciones radiculares son uno de los riesgos que se toman al tratar endodónticamente los dientes y depende del operador que este accidente no sea el final del diente afectado. Son una de las causas inminentes de fracasos endodónticos y son denominadas en términos de aperturas artificiales en las paredes radiculares creadas por el fresado, taladrado, corte o resorción que causa una comunicación entre el espacio pulpar y los tejidos periodontales, lo que puede producir una complicación periodontal secundaria y la eventual pérdida del diente. Estas pueden ser inducidas por iatrogenia, procesos resortivos o por caries. El objetivo de este artículo es hacer una revisión sobre los factores que intervienen en las perforaciones radiculares. [0jeda CA. Perforaciones radiculares: Una revisión. Ustasalud Odontología 2004; 3: 92 - 99]
\end{abstract}

Palabras clave: Perforaciones radiculares, Stripping.

\section{ROOT PERFORATIONS: A REVIEW}

\begin{abstract}
Root perforations are one of the risks when endodontically treating the teeth and depend on the operator that this accident will not be the end of the affected tooth. Root perforations are one of the causes of endodontic failures and are denominated in terms of artificial openings in the root walls created by the milled one, drilled, cut or resorption that turns out in a communication between the pulp space to periodontal tissues, that could cause a secondary periodontal complication and a possible lose of the tooth. They can be induced by introgenic causes, resorptives processes or by decay. The purpose of this paper was to review the factors that affect this failure.
\end{abstract}

Key words: Root perforations, Stripping.

Recibido para publicación: 8 de septiembre de 2004. Aceptodo para publicadion: 10 de octubre de 2004 .

\section{INTRODUCCIÓN}

El mantenimiento de la integridad de la dentición natural es esencial para las condiciones funcionales y estéticas. El tratamiento endodóntico es el último intento para alcanzar esta meta; su falla pone en peligro la existencia del diente y potencialmente produce desórdenes estéticos y funcionales.

Las perforaciones radiculares son uno de los riesgos que se toman al tratar endodónticamente los dientes; de nosotros depende que este accidente no sea el final del diente afectado. Actualmente contamos con muchas herramientas diagnósticas, materiales y técnicas adecuadas para el manejo de estas situaciones.

\section{DEFINICIÓN}

Se ha encontrado que las perforaciones radiculares son una de las causas más frecuentes de los fracasos endodónticos. Se conocen como aperturas artificiales en las paredes radiculares creadas por el fresado, taladrado, corte o resorción que genera en una comunicación entre el espacio pulpar y los tejidos periodontales, que puede causar una complicación periodontal secundaria y la eventual pérdida del diente. ${ }^{1}$ Las perforaciones radiculares pueden ser inducidas por causas iatrogénicas, procesos resortivos o por caries.

\section{Perforaciones iatrogénicas:}

Frecuentemente se deben a la falta de atención de los 
detalles de la anatomía interna y una falla en la consideración de las variaciones anatómicas; de ahí la importancia de la toma y el análisis de las radiografias iniciales. Las perforaciones de la cámara pulpar pueden ocurrir cuando la cámara está casi totalmente calcificada, como resultado de un proceso de envejecimiento o como reacción a un trauma o a un irritante. Si el piso y el techo de la cámara pulpar están muy próximos, la perforación se puede presentar por descuido, al introducir la fresa por el piso relativamente estrecho. ${ }^{2}$ La perforación también puede generarse por un retiro inadecuado del techo de la cámara pulpar que, resultante de una dirección errada de la fresa, durante la preparación de la cavidad de acceso. ${ }^{3}$ En un diente con malposición, la perforación puede resultar cuando la fresa no es bien angulada con relación al eje longitudinal del diente. Hay profesionales que recomiendan preparar la cavidad de acceso sin colocar el dique de goma, para visualizar mejor la corona del diente tratado en relación con las coronas de los dientes vecinos y, de alguna forma, prevenir este tipo de accidentes. El estrecho diámetro mesodistal, en el cuello de los premolares inferiores y la inclinación hacia lingual de sus raíces, incrementa la frecuencia de las perforaciones

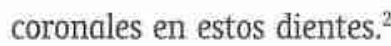

\section{Perforaciones en cinta (strippings):}

Pueden resultar del ensanchamiento excesivo del tercio coronal de conductos curvos estrechos o por adelgazamiento extremo de las paredes radiculares con una eventual perforación. ${ }^{5}$ El gran tamaño y bordes irregulares hacen del sellado de esta perforación una tarea un poco complicada. Los instrumentos endodónticos intentan enderezarse por si mismos, dentro de estos conductos y causan escalones o perforaciones de la pared de la furca 0 en el tercio apical cuando hay una curvatura marcada. Esto puede evitarse con el precurvado de las limas o con el uso de limas de níquel-titanio. El área de la furca en el tercio coronal de Ias raices estrechas curvas se ha descrito como zona de peligro ("danger zone»); ${ }^{4}$ hay menos estructura dentaria en este sector, comparada con la pared extema del conducto. Una tendencia a remover dentina de esta zona incrementa la frecuencia de perforaciones en cinta, especialmente con preparaciones de acceso, que no son en línea recta. Estas perforaciones ocurren, usualmente, sobre la superficie distal de las raices mesovestibulares de los molares superiores y las raices mesiales de los molares inferiores cerca del área de la furca. ${ }^{6}$
Las perforaciones en el nivel del tercio medio radicular pueden resultar de intentos descuidados en la preparación de los conductos con pulpolitos, corrección de escalones 0 en el sobrepaso de instrumentos fracturados, ${ }^{7}$ un instrumento en una mala orientación durante la búsqueda de un conducto radicular puede resultar en la creación de un falso conducto especialmente en raíces curvas. ${ }^{8}$ Otra causa de este tipo de perforaciones es el uso inadecuado de instrumentos rotatorios en la preparación para postes y núcleos. ${ }^{9}$

Las perforaciones apicales pueden ocurrir como resultado de la instrumentación del conducto radicular más allá de su forámen apical anatómico. La transportación de la región apical puede ocurrir por el enderezamiento del instrumento, por sí mismo, apicalmente, dentro de los conductos curvos cortando la pared dentinal externa de la curvatura más que la pared interna. Si la preparación continúa puede producir una perforación tipo zipping. ${ }^{4}$

La prevención de las perforaciones radiculares iatrogénicas ha sido explicada por diversos autores, quienes, basados en su experiencia, dan algunas recomendaciones. Por ejemplo, Harris estipuló que la perforación puede prevenirse con un adecuado acceso al conducto radicular, doblando los instrumentos para acomodarse a la curvatura del conducto antes de insertarlos. ${ }^{10} \mathrm{Sin}$ embargo, el advenimiento de limas de níquel-titanio, con flexibilidad mejorada, permite a las limas seguir la curvatura del conducto. Esto hace que ya no sea necesario precurvar las limas. ${ }^{11}$ Harris propone que la preparación del espacio para postes con el uso de limas o ensanchadores (reamers), y con solvente, es más segura que el uso de fresas, aunque puede dañar el remanente de gutapercha en apical.

Perforaciones por resorciones internas o externas: La comunicación entre el espacio pulpar y las estructuras periodontales pueden ocurrir como resultado de un proceso resortivo, si a éste se le ha dado el tiempo necesario. Esta resorción puede ser interna o externa. ${ }^{12}$

La resorción interna es un proceso fisiológico o patológico, originado en la cavidad pulpar, resultado de la pérdida de estructuras radiculares. ${ }^{1}$ Aunque el trauma, ${ }^{13}$ la inflamación pulpar y la pulpotomía con hidróxido de calcio han sido sugeridas como posibles causas de la re- 
sorción radicular interna, la causa exacta es incierta. ${ }^{14}$ Este proceso es usualmente asintomático y puede destruir fácilmente el diente, en casos no tratados.

La resorción externa, que lleva a una perforación, ha sido atribuida principalmente al trauma por el aplastamiento del ligamento periodontal y, posiblemente, la muerte pulpar induce reacciones inflamatorias, que culminan en una actividad odontaclástica. ${ }^{14}$ El tejido inflamatorio en las bolsas periodontales ha sido sugerido como otro mecanismo de resorción externa. ${ }^{15}$ Aunque se han reportado casos de resorción externa después de procedimientos de blanqueamiento, ${ }^{16}$ ésta también puede ser idiopática y, generalmente, produce un despuntamiento del ápice. La naturaleza de este proceso resortivo es probablemente sistémica; su ocurrencia es poco frecuente..$^{15}$

\section{Perforaciones por caries:}

Se pueden producir perforaciones por caries en el caso de la invasión del piso de la cámara pulpar y su subsiguiente extensión hacia la furca, en casos de gran negligencia. Sin embargo, esto no se considera, generalmente, una perforación endodóntica, sino un problema restaurador - periodontal. ${ }^{12}$

\section{CL.ASIFICACIÓN Y PRONÓSTICO}

Trope, en 1996, publicó una clasificación basada en diversos factores, que afectan el pronóstico de las perforaciones radiculares. ${ }^{17}$ Esta clasificación ayudará en el momento de la elección del tratamiento, y también en el momento de consultar con el paciente nuestras expectativas con respecto del procedimiento por efectuar. Esos factores son el tiempo, el tamaño y la localización.

\section{Tiempo:}

El tiempo entre la ocurrencia de la perforación y la realización de un tratamiento se ha señalado como factor importante en la cicatrización. ${ }^{1820}$ Lantz y Persson, experimentalmente, produjeron perforaciones radiculares en perros, y luego las trataron inmediatamente, o después de un tiempo. ${ }^{20}$ La cicatrización más favorable ocurrió cuando las perforaciones fueron selladas inmediatamente. De este modo disminuyó la probabilidad de la infección con un mejor ambiente perirradicular alrededor de la perforación. Seltzer y colaboradores estudiaron 22 perforaciones en monos; fueron tratadas en diferentes rangos de intervalo, desde inmediatamente hasta 10 meses después. ${ }^{18}$ El periodonto fue dañado en todos los dientes involucrados; pero el daño más severo se encontró en las perforaciones sin tratar y en los dientes que fueron tratados más tardíamente. Beavers encontró una alta tasa de éxito, en cicatrización periodontal, atribuida principalmente a una obturación inmediata de las perforaciones y a la técnica aséptica. En otras palabras, buen selle y ausencia de infección. ${ }^{19}$

\section{Tamaño:}

Una perforación pequeña está asociada usualmente con menos destrucción del tejido y menor inflamación; además, la cicatrización es más predecible. Himel y colaboradores evaluaron el efecto de tres materiales sobre la reparación biológica de un defecto creado por medio de la perforación del piso de la cámara pulpar de dientes mandibulares posteriores, de perros. ${ }^{21}$ Encontraron que el pronóstico del tratamiento fue directamente proporcional al tamaño de la perforación. Parece lógico pensar que las perforaciones pequeñas tienen un mejor pronóstico, por ser más fáciles de sellar efectivamente, sin forzar el material de obturación dentro de los tejidos de soporte.

\section{Localización:}

La localización de la perforación es probablemente el factor más importanteen el pronóstico del tratamiento. Una cercana proximidad de la perforación al surco gingival permitirá contaminación del sitio de la perforación, con bacterias de la cavidad oral, a través del surco. Además, si la herida es grande y no es tratada inmediatamente, la proximidad de la unión epitelial es crítica y la migración apical del epitelio hacia el sitio de la perforación creará un defecto periodontal. ${ }^{19}$

En la figura 1, se encuentran otros factores importantes en el pronóstico de las perforaciones radiculares. Las definiciones, según Fuss \& Trope, son: ${ }^{17}$

\section{* Tiempo:}

Perforaciones recientes: asociadas con una perforación en la misma visita; si son tratadas inmediatamente y con técnica aséptica tienen un buen pronóstico.

Perforaciones antiguas: asociadas con procedimientos operatorios accidentales, sin previo tratamiento, donde una infección bacterial puede establecerse, tienen mal pronóstico. 


\section{* Tamaño:}

Perforaciones pequeñas: son las que se producen con instrumentos de endodoncia como las limas 15 y 20. El daño mecánico en el tejido es mínimo, y la probabilidad de que la perforación ocurra en condiciones asépticas (irrigación con hipoclorito de sodio, uso de tela de caucho) la hace más favorable, pues la instauración de un proceso infeccioso es poco probable.

Perforaciones grandes: pueden ocurrir en preparaciones para postes; producen un significativo daño tisular, y las posibilidades de infección, a partir de la saliva y la filtración, son mucho mayores.

* Localización: La posición de la perforación se fija en relación con los tejidos de soporte y no solamente con su posición en la raíz.

Perforación coronal: están localizadas coronal a la cresta ósea y el epitelio de unión; tienen un mal pronóstico.

Perforación crestal: perforaciones localizadas en el nivel del epitelio de unión y del hueso alveolar; su pronóstico es pobre.

Perforación apical: localizadas apical a la cresta ósea y al epitelio de unión; tienen buen pronóstico.

Adicionalmente, las perforaciones laterales se consideran de buen pronóstico, pues, generalmente, pueden encontrarse tanto en coronal como en apical; el pronóstico de las perforaciones de furca es malo ya que, usualmente, se encuentran cercanas a la cresta ósea y al epitelio de unión.

\section{Perforaciones Radiculares laterales o furcales}

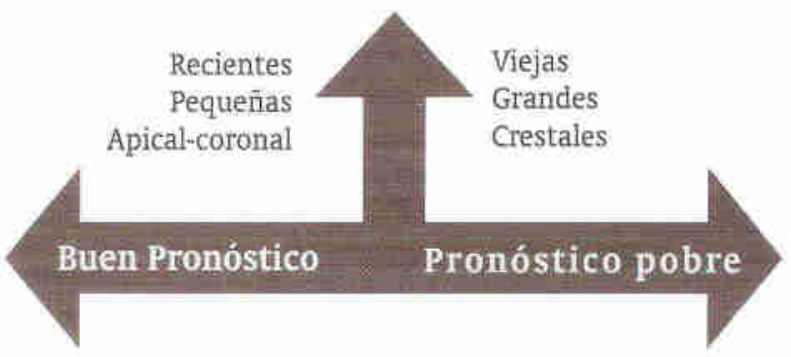

Figura 1. Clasificación de las perforaciones radiculares de acuerdo con los factores que afectan el pronóstico. ${ }^{17}$

\section{DIAGNÓSTICO}

El diagnóstico de las perforaciones iatrogénicas requiere una combinación de hallazgos sintomáticos y observaciones clínicas. La pista acerca de una posible perforación ocurre cuando se coloca una lima o ensanchador en la apertura, y el instrumento parece estar flojo, en vez de estar ajustado, como se esperaría, en un conducto real. ${ }^{1}$ Se puede saber de la presencia de una perforación de varias maneras. Por ejemplo, el sangrado constante en el conducto y las puntas de papel empapadas de sangre continuamente. Se puede visualizarla en una radiografía o localizándola electrónicamente con un Localizador Apical Electrónico (LAE). O incluso por la sintomatología del paciente durante el procedimiento operatorio.

Una observación frecuente de sangrado, dentro del espacio pulpar, puede ser la primera evidencia de una perforación iatrogénica. La perforación de la cámara pulpar puede causar sangrado de los tejidos blandos adyacentes o del ligamento periodontal. La presencia de sangre en la mitad del piso de la cámara pulpar de un molar indica una posible perforación en el área de la furca. El sangrado como flujo repentino, durante la preparación del conducto, indica una perforación en cinta (stripping) de las paredes del conducto.

Las puntas de papel son útiles en la evaluación de las perforaciones radiculares. La sangre que aparece a lo largo del costado de una punta de papel, pero no en la punta, puede indicar una perforación lateral o en cinta. La inserción repetida de puntas de papel que salen embebidas en sangre, en la punta, indica una perforación apical. Esto puede confirmarse por medio de la irrigación cuidadosa del conducto, sin llevar el irrigante a los tejidos que rodean la perforación, si usa una punta de papel para secar el conducto.

El diagnóstico de una perforación radicular, usualmente, es difícil. Cuando éstas están localizadas sobre el lado vestibular o lingual de la raiz, la perforación es superpuesta radiográficamente sobre la superficie radicular. El clínico debe sondear el surco gingival para evaluar una posible comunicación con la cavidad oral. ${ }^{17}$ Un Localizador Apical Electrónico (LAE) es útil en la localización exacta de la comunicación con el ligamento periodontal. $^{22}$

Kaufman y colaboradores, en 1997, concluyeron que la nueva generación de LAE debe ser considerada como una 
ayuda real de equipo en la detección de perforaciones radiculares. ${ }^{37}$

Nahmias, en el 2001, concluyó que los localizadores apicales son útiles en la detección de una perforación; pero no menciona la ubicación de las perforaciones. ${ }^{2 .}$ En cuanto a la evaluación radiográfica, Gutmann aseguró que la detección radiográfica de perforaciones, hacia la raíz bucal o lingual, no es práctica porque la imagen de la perforación se sobrepone a la imagen de la raiz.. ${ }^{24}$ Fuss y colaboradores encontraron otras desventajas de las radiografias que incluyen (1) las estructuras anatómicas y los materiales radiopacos pueden sobreponerse a la imagen de la raíz; (2) el procedimiento consume tiempo; (3) los pacientes, con reflejo de nausea, pueden evitar la toma de radiografias; (4) la exactitud de las radiografias es limitada, y (5) existe riesgo biológico de radiación. ${ }^{17}$ La limitación de la exactitud de las radiografias ha sido corregida, en gran parte, con la técnica del paralelismo (cono largo) y la utilización de instrumentos diseñados con este fin (Endoray).

\section{Técnica de exploración triangular:}

Puede usarse para determinar la posición exacta de las curvaturas radiculares, y también los errores iatrogénicos, como escalones, creación de falsas vías durante la preparación del espacio para postes y perforaciones laterales. Esta técnica propone la toma de tres radiografias: una con la angulación normal, y las otras con angulaciones mesiales y distales, preferiblemente de $20^{\circ}$, como lo descrito por Clark en 1910 y Richards en $1980{ }^{25,26}$ El fundamento de esta técnica consiste en que la visualización de curvaturas o defectos es imposible cuando se superponen sobre el espacio del conducto. Para interpretar los datos, provenientes de estas tres radiografias correctamente, es necesario dibujar un diagrama por cada vista con dos círculos concéntricos; donde el círculo de afuera representa el contorno de la raíz y el círculo de adentro, el contorno del conducto. Cada sección de corte que representa la raíz, se divide, luego, en cuadrantes por dos lineas, una vertical que divide la raiz en mesial y distal y una horizontal, que las divide en vestibular y lingual. Claramente, la angulación mesial, superpondrá los cuadrantes mesovestibular (MV) y distolingual (DL), mientras que la angulación distal superpondrá los cuadrantes distovestibular (DV) y mesolingual (ML). Los datos obtenidos con estas tres radiografias se transfieren a los diagramas para producir una simple representación de la compleja arquitectura tridimensional del diente, hueso circundante, estructuras anatómicas asociadas y patología apical. Con esta técnica, la localización de las perforaciones, instrumentos fracturados y fresas, puede reducirse y lograr un tratamiento más sencillo y más seguro.

En cuanto a la sintomatología del paciente puede incluirse dolor repentino, durante los procedimientos operatorios, que indican que una lima penetra el hueso circundante. Es probable que esta respuesta se dé si la anestesia es poco profunda o no se ha anestesiado. Otra respuesta del paciente es el reporte de la sensación del sabor de las soluciones irritantes, lo cual puede indicar una perforación cervical.

Adicionalmente, la perforación existente, no tratada, puede detectarse por la presencia de un exudado seroso en el sitio de la perforación, sensibilidad a la percusión del diente afectado, y por la inflamación crónica de la encía, cuando la perforación ha penetrado el hueso alveolar. Además, la presencia de un tracto sinuoso o los problemas localizados, como una bolsa periodontal o problemas de furca, después de un aparentemente buen tratamiento endodóntico puede indicar la existencia de una perforacion. ${ }^{27}$

\section{TRATAMIENTO}

De acuerdo con el acceso y la visibilidad de la perforación, la corrección puede ser quirúrgica o no quirúrgica. Además también hay que incluir, dentro de esos criterios, el tamaño de la perforación, las condiciones periodontales del paciente, la higiene oral, la importancia estratégica del diente y la experiencia del operador. Aunque Alhadainy asegura que los dientes con poca importancia estratégica y una mala higiene oral del paciente deben ser extraídos, la misión del endodoncista es la de conservar los dientes en la boca y mejorar las condiciones del paciente. ${ }^{1}$

Reparación no quirúrgica, Se afecta por factores importantes como visibilidad y humedad del medio en que se trabaja; en algunos casos, incluso la estética. La reparación de perforaciones coronales usualmente puede hacerse con un material de restauración dentocoloreado, de tal forma que no se vea afectada la estética dental (en este caso la cosmética) y se asegure un sellado óptimo del problema o si es muy grande, se recomienda una corona 
colada. Las perforaciones subgingivales, ligeramente apicales a la cresta ósea, pueden tratarse con una técnica ortodóntico-endodóntica, para lograr que el diente afectado sea extruído y elevar la perforación arriba de la cresta ósea. De esta manera, no se realizaría una cirugía compleja. ${ }^{29}$ Las limitaciones de esta técnica son: mucho tiempo en la extrusión y estabilización; requiere un costo mayor. Su mayor ventaja es sellar la perforación inclusive sin tratamiento quirúrgico. ${ }^{30}$

Las perforaciones del piso de la cámara pulpar (perforaciones de furca) o del tercio coronal de la raiz pueden ser tratadas no quirúrgicamente, si tenemos acceso adecuado a través de la cámara. Algunos autores aconsejan realizar una preparación retentiva en el defecto y colocar un material de restauración dentro de la perforación, sin extruir demasiado material fuera del defecto. ${ }^{31-39}$ Cohen y Burns aseguran que la mayor dificultad de este método de reparación es que el defecto actúa como una fisura sin fondo y es muy común la extrusión del materia hacia el espacio periodontal..$^{35}$

Inicialmente, se estudiaron algunos materiales como la amalgama, la gutapercha, el hidróxido de calcio y el cavit, para obturar perforaciones radiculares. Posteriormente, la investigación se centro en las matrices internas, biológicamente inertes. En 1969, Auslander y Weinberg lo hicieron utilizando con lamina de indio, contra la que empacaban amalgama; también se utilizaron chips de dentina, hidróxido de calcio, discos de teflón, hidroxiapatita (HA), yeso de Paris y actualmente el Mineral Trioxido Agregado (MTA). Todo esto con el fin de evitar la extrusión del material en el espacio periodontal del defecto y permitir un mejor ambiente para un material restaurador, seco, firme y limpio.

La toxicidad de algunos materiales de obturación de perforaciones fue evaluada por Tai y Chang en el 2000. Encontraron que aunque los materiales utilizados eran citotóxicos para las células del ligamento periodontal in vitro, no presentaban efectos tóxicos en la clínica. ${ }^{38}$

Allam, en 1996, propuso una técnica, en dos pasos, para la obturación de perforaciones en cinta o tipo stripping. en donde el conducto es sellado, en un primer paso, con gutapercha; se busca una sobreobturación hacia el sitio de la perforación; en un segundo paso, el exceso de material es removido quirúrgicamente; se bruñe en el sitio del defecto. ${ }^{5}$ Con esta técnica se evitan las amputaciones radiculares, único tratamiento en tiempos anteriores.
La reparación de las perforaciones apicales se realiza como un tratamiento endodóntico convencional (como si fuese otro conducto); la dificultad radica en la preparación y obturación del conducto principal ya que el instrumento tratará de seguir una falsa vía. Las perforaciones pequeñas, generalmente, se pueden tratar en una sola cita; las de un diámetro mayor y/o viejas deben tratarse con un medicamento intraconducto, como el hidróxido de calcio; las pequeñas se obturan en una segunda visita, y las más grandes deben tratarse como un diente con ápice inmaduro, ${ }^{17}$ Trope y Tronstad reportaron éxito en el tratamiento de una perforación lateral con el uso de hidróxido de calcio después de un año de tratamiento. ${ }^{36}$ Aunque actualmente está disponible el MTA (Mineral Trióxido Agregado), que podría hacer mucho más rápido el procedimiento (tapón apical de MTA).

Este ha sido utilizado recientemente en muchas situaciones clínicas, que incluyen la reparación de perforaciones radiculares de todo nivel. Sus propiedades y experiencias clínicas merecen ser revisadas.

El MTA es un polvo de finas partículas hidrofilicas que endurecen en presencia de humedad. ${ }^{39}$ La hidratación del polvo produce un gel coloidal con un $\mathrm{pH}$ de 12.5 , que solidifica hasta ser una estructura dura. El tiempo de endurecimiento del cemento es de aproximadamente cuatro horas, la resistencia compresiva a los 21 días es de aproximadamente $70 \mathrm{MPa}$, comparable con la del IRM o el super-EBA, pero significativamente menor que la amalgama $(311 \mathrm{MPa}) .^{40}$ Las desventajas del material son su dificil manipulación en este tipo de situaciones y su tiempo de fraguado prolongado.

Reparación quirúrgica. El acceso quirürgico es limitado usualmente a los defectos, a los que no es posible llegar de otro modo.' Algunas veces el acceso quirúrgico a las perforaciones radiculares es difícil, especialmente en la cara lingual de los molares mandibulares o en la trifurcación maxilar. En tales situaciones dicho acceso conducirá a la formación de una bolsa periodontal crónica y problemas de furca.

La reparación quirúrgica de una perforación radicular ha sido intentada reflejando un colgajo en el sitio de la perforación. El material restaurador se empaca dentro del defecto a través del acceso quirúrgico. ${ }^{41}$ Nicholls resumió las indicaciones de las reparaciones quirúrgicas, en perforaciones grandes, inaccesibles por vía no quirúr- 
gica, perforaciones resultantes de una resorción y falla en la cicatrización después de la reparación quirúrgica. ${ }^{9}$ Stromberg y colaboradores adicionaron a estas indicaciones la necesidad de retiro de grandes sobreobturaciones de defectos y SINAB, en 1977, la presencia de postes y coronas cementadas o las restauraciones coronales extensas. ${ }^{12,43}$

Las perforaciones pueden sellarse mediante las dos técnicas mencionadas anteriormente, de tal forma que se selle, no quirúrgicamente, el defecto, se sobreobture intencionalmente y luego se remueva el exceso de material, por medio de un colgajo quirúrgico.

Las grandes perforaciones de furca pueden ser tratadas por biscuspidación (premolarización), hemisección o amputación radicular. Esta elección depende del nivel de la cresta ósea y su relación con la furca, el grado de convergencia de la raíz hacia la furca y la longitud de la raíz.

Las perforaciones grandes e inaccesibles, hacia la mitad de la raíz o las perforaciones por resorción, interna $\mathrm{o} \mathrm{ex}$ terna, pueden ser tratadas por reimplantación intencional, ${ }^{43,44}$ aunque Luebke asegura que esta opción quirúrgica debe ser la última a ser tenida en cuenta. ${ }^{41}$

\section{CONCLUSIÓN}

Aunque las perforaciones radiculares iatrogénicas incrementan significativamente las fallas en endodoncia, se encuentran estudios en la literatura acerca de técnicas, materiales y elementos para diagnosticar y tratar adecuadamente este tipo de problemas.

\section{BIRLIOGRAFIA}

1. Alhadainy HA. Root perforations. A review of literature. Oral Surg Oral Med Oral Pathol 1994: 78: 368 - 374.

2. Grossman LI. The management of accidents encountered in endodóntico practice. Dent Clin North Am 1957; 11: 903 - 912.

3. Weisman ML. Treatment of an unusual of an anterior tooth. Oral Surg Oral Med Oral Pathol 1959; 12: 732 - 735.

4. Waiton RE, Torabinejad M. Principles and practice of endodontics. Philadelphia: WB Saunders, 1989: 210.

5. Allam CR. Treatment of stripping perforations. J Endod 1996; 22: $699-702$.
6. Gutmann JL, Dumsha TC, Lovdahl PE. Problem solving in endodontics, 2nd ed. St. Louis: Mosby year book; $1992: 80-84$.

7. Gutmann JL, Dumsha TC, Lovdahl PE. Problem solving in endodontics, and ed. St. Louis Mosby year book; 1992: 190 - 196.

8. Jew RC, Weine SW, Keene JJ, Smulson MH. A histologic evaluation of periodontal tissues adjacent to root perforations filled with Cavit. Oral Surg Oral Med Oral Pathol 1982; 52: 124 - 135.

9. Nicholls E. Treatment of traumatic perforation of the pulp cavity. Oral Surg Oral Med Oral Pathol 1962; 15: 603 - 612.

10. Harris WE. A simplified method of treatment for endodontic perforation. JEndod 1976; 2: 126 - 134.

11. Walia $\mathrm{H}$, Brantley WA, Gerstein $\mathrm{H}$. An initial investigation of the bending and torsional properties of nitinol root canal files. J Endod 1988: $14: 341-351$.

12. Sinai $T H$. Endodontic perforations: their prognosis and treatment. J Am Dent Assoc. 1977; 95; 90 -95

13. Vajda TI. Treatment of internal resorption involving lateral perforation by immediate root resection technique. Aust Dent $\mathrm{J} 1969$; 14: $325-326$.

14. Chivian N. Resorción radicular. En: Cohen S, Burns RC. Caminos de la Pulpa, 5th ed. St. Louis: CV Mosby Co; 1991.

15. Deeb E. Idiopathic resorption of permanent teeth. JS Calif Dent Assoc $1960 ; 28: 210$.

16. Al - Nazhan S. External root resorption after bleaching: a case report. Oral Surg Oral Med Oral Pathol 1991; 72; 607 - 679.

17. Fuss Z, Trope M. Root Perforations: classification and treatment choice based on prognostic factors. Endod Dent Traumatol 1996; 12: $255-264$.

18. Seltzer S. Sinai IH, August D. Periodontal effects of root perforations before and during endodontic procedures. J Dent Res 1970; 49: 332 339 .

19. Beavers RA, Bergenholtz G, Cox CF. Periodontal wound healing following intentional root perforations in permanent teeth of Macaco mulatto. Int Endod J 1986; 19: 36 - 44.

20. Lantz B, Persson PA. Periodontal tissue reactions after root perforations in dog's teeth - a histological study. Odontol Tidskrift 1976: $75: 209-220$.

21. Himel VT, Brady J. Weir J. Evaluation of repair of mechanical perforations of the puip chamber floor using biodegradable tricalcium phosphate or calcium hydroxide. J Endod 1985; 11: 161 - 165.

22. Fuss Z, Assooline LS, Kaufman AY. Determination of location of root perforations by electronic apex locator. Oral Surg Oral Med Oral Pathol 1996; 82: 324 - 329. 
23. Nahmias Y. Diagnosing perforations using apex locator. Endodontic Practice 2001; 26 - 30.

24. Gutmann JL, Harrison JW. Surgical endodontics. Boston: Blackwell Scientific Publications, 1991: 409 - 442.

25. Clarck CA. A Method of ascertaining the relative position of unerupted teeth by means of film radiographs. Odont Sec $\mathrm{R}$ Soc Med Trans 1987; 3: 1909-1910.

26. Richards AG. The buccal object rule. Dent Radiog Photog 1980; 53 : 37.

27. Taatz H, Stiefel A. Zur therapie von zhanperforationen. Zhanaerztliche Welt 1965; 66: 814 - 819 .

28. Lemon RR. Reparación no quirúrgica de perforaciones. Concepto de matriz interna. Dent Clin North Am 1992; 36.

29. Simon JH, Kelly WH, Gordon DG, Erickson GW. Extrusion of endodontically treated teeth. J Am Dent Assoc 1978; 97: 17 - 23.

30. Oswald JB. Procedural accidents and their repair. Dent Clin North Am 1979; 23: 593-616.

31. Cathey GM. Molor endodontics. Dent Clin North Am 1974; 18: 345 $-366$.

32. Benson WE, Colonel L, Del Río CE. Amalgam in endodontics. Oral Surg Med Oral Oral Pathol 1963; 16: 1498 - 1507.

33. Grossman LI Endodontic failures. Dent Clin North Am 1972; 16: 59 -70 .

34. Cattoni M. Common failure in endodontics and their correction. Dent Clin North Am 1963: 7: 383 -399.

35. Cohen S, Burns RC. Pathways of the pulp, 2nd ed. St. Louis: CV Mosby Co; 1980 .

36. Trope M. Tronstad L. Long-term calcium hydroxide treatment of a tooth with iatrogenic root perforation and lateral peridodontitis. Endod Dent Traumatol 1985; 1: 35 - 38.

37. Kaufman AY, Fuss Z, Keila S, Waxenberg S. Reliability of different electronic apex locators to detect root perforations in vitro. Int Endod J 1997; 30: 403 - 407 .

38. Tai K, Chang Y. Cytotoxicity evaluation of perforation repair materials on human periodontal ligament cells in vitro. JEndod 2000; 26: $395-397$.

39. Torabinejad M, Hong CU, Pitt Ford TR. Physical properties of a new root end filling material. J Endod 1995; 21: 349 - 353.

40. Torabinejad M, Chivian N. Clinical applications of mineral trioxide aggregate. JEndod 1999; 25: 197 - 205.

41. Luebke RG, Glick DH, Ingle JI. Indications and contraindications for endodontic surgery. Oral Surg oral Med Oral Pathol 1964: 18:97 - 113.
42. Stromberg T, Hasselgren G, Bergstedt H. Endodontic treatment of traumatic root perforation in man. Swed Dent J 1972; 65: 457 - 466 .

43. Messing JJ. Planned re-implantation. J BR Endo Soc 1970; 3: 2.

44. Grossman II. Intentional Replantation of teeth. J Am Dent Assoc 1966; $72: 1111-1118$.

\section{Especializaciones ên ODOVTOLOGÍA}

ODONTOPEDIATRIAA 170558170616800111100

口

ENDODONCIA。 170556170636800111100

ORTODONCIA。 170556170646800111100
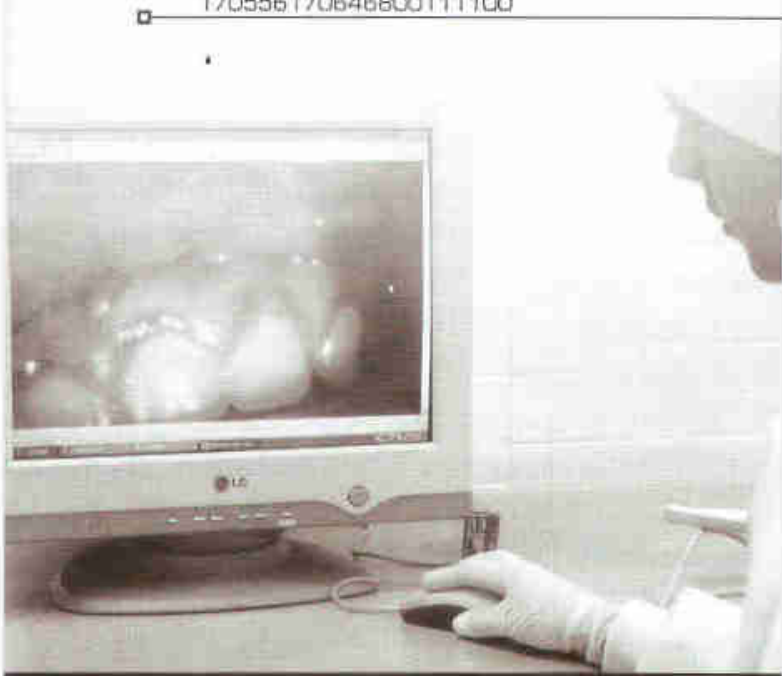

FACULTAD DE ODONTOLOGIA CAMPUS DE FLORIDABLANCA - EDIFICIO SAMTANDER www.ustahuca.ediu.co

99 